\title{
PENGARUH EMPLOYEE ENGAGEMENT KARAKTERISTIK INDIVIDU DAN DISIPLIN KERJA TERHADAP PRESTASI KERJA PEGAWAI DI KANTOR KECAMATAN MEDAN BELAWAN
}

\author{
Ahmad \\ Universitas Islam Sumatera Utara \\ ahmad.mm@gmail.com
}

\begin{abstract}
The formulation of the problem in this study is how the influence of employee engagement on employee performance. How does the influence of individual characteristics on employee performance. How is the influence of work discipline on employee performance. How does the influence of employee engagement individual characteristics and work discipline on employee performance.The purpose of this study was to determine the effect of employee engagement on employee performance. To determine the effect of individual characteristics on employee performance. To influence the influence of work discipline on employee performance. To influence employee engagement individual characteristics and work discipline on employee performance.

The sample in this study amounted to 47 people. Data analysis techniques in this study used descriptive analysis and multiple linear regression analysis.

The results of this study explain that employee engagement has a positive and significant effect on employee performance. Individual characteristics have a positive and significant effect on employee performance. Work discipline has a positive and significant effect on employee performance. Employee engagement of individual characteristics and work discipline has a positive and significant effect on employee work performance.
\end{abstract}

Keywords : Employee engagement, individual characteristics, work discipline, work performance

\begin{abstract}
ABSTRAK : Rumusan masalah dalam penelitian ini adalah bagaimana pengaruh employee engagement terhadap prestasi kerja pegawai. Bagaimana pengaruh karakteristik individu terhadap prestasi kerja pegawai. Bagaimana pengaruh disiplin kerja terhadap prestasi kerja pegawai. Bagaimana pengaruh employee engagement karakteristik individu dan disiplin kerja terhadap prestasi kerja pegawai.Tujuan dari penelitian ini adalah untuk mengetahui pengaruh employee engagement terhadap prestasi kerja pegawai. Untuk mengetahui pengaruh karakteristik individu terhadap prestasi kerja pegawai. Untuk mempengaruhi pengaruh disiplin kerja terhadap prestasi kerja pegawai. Untuk mempengaruhi employee engagement karakteristik individu dan disiplin kerja terhadap prestasi kerja pegawai. Sampel dalam penelitian ini berjumlah 47 orang. Teknik analisis data dalam penelitian ini menggunakan analisis deskriptif dan analisis regresi linier berganda. Hasil penelitian ini menjelaskan bahwa employee engagement berpengaruh positif dan signifikan terhadap prestasi kerja pegawai. Karakteristik individu berpengaruh positif dan signifikan terhdap prestasi kerja pegawai. Disiplin kerja berpengaruh positif dan signifikan terhadap prestasi kerja pegawai. Employee engagement karakteristik individu dan disiplin kerja berpengaruh positif dan signifikan terhadap prestasi kerja pergawai.
\end{abstract}

Kata kunci : Employee engagement, Karakteristik individu, Disiplin kerja, Prestasi kerja.

\section{Pendahuluan}

Pada dasarnya, sumber daya manusia adalah suatu sumber daya yang sangat dibutuhkan oleh suatu organisasi. Pegawai merupakan salah satu sumber daya organisasi yang mempunyai nilai prakarsa dan memiliki peran penting dalam pemberdayaan sumber daya lainnya dalam organisasi. Sistem pengelolaan Sumber Daya Manusia (SDM) yang tepat merupakan kunci keberhasilan organisasi untuk mencapai tujuan organisasi. Oleh karena itu, agar tujuan dan sasaran organisasi dapat 
dicapai, perlu adanya perhatian yang lebih dari organisasi terhadap upaya-upaya dalam meningkatkan kinerja pegawai.

Peningkatan kinerja pegawai dapat dipengaruhi oleh beberapa faktor, salah satunya yaitu ketersediaan fasilitas kerja, meskipun fasilitas kerja hanya sebagian kecil dari faktorfaktor yang mempengaruhi kinerja, namun keberadaannya tidak bisa diabaikan begitu ssaja. Sebab, tanpa adanya fasilitas kerja kegiatan organisasi tidak akan dapat terlaksana dengan baik sesuai dengan tujuan yang diharapkan. Fasilitas kerja sangat dibutuhkan dalam kegiatan organisasi secara formal yang pada umunya berlangsung di suatu organisasi. Menurut Nitisemito (2009:88) mengemukakan bahwa fasilitas kerja merupakan kelengkapan kerja yang harus dimiliki organisasi. Fasilitas kerja dinas saat ini juga belum begitu mendukung karena masih kurangnya sarana dan prasaran seperti internet, media informatika, ruang kerja yang nyaman, alat transportasi, dan berbagai sarana pendukung lainnya. Ruang kerja dan perlengkapan kantor yang baik sangat mendukung kenyamanan pegawai yang akan meningkatkan efesiensi dan efektifitas pegawai dalam bekerja. Faktor-faktor lainnya yaitu lingkungan kerja, tanggung jawab, visi misi dan budaya organisasi, sistem komunikasi organisasi, pelatihan dan pengembangan diri, dan bonus maupun insentif yang harus disesuaikan dengan kepentingan dan pentingnya organisasi itu sendiri.

Pentingnya organisasi instansi Kantor Kecamatan Medan Belawan untuk mewujudkan tujuan dari instansi pemerintah sendiri diperlukan organisasi instansi pemerintahan yang berlangsung secara tertib dengan ditandai adanya pengaturan, pembagian tugas, cara kerja dan hubungan antara pekerjaan yang satu dengan pekerjaan yang lain. Atau dengan kata lain diperlukan suatu manajemen instansi pemerintahan yang baik agar pekerjaan tersebut dapat berjalan lebih lancar, cepat, tepat, efektif, dan efisien, agar dapat mewujudkan dan melaksanakan tugas-tugas pemerintahan tersebut, mutlak diperlukan adanya aparatur instansi pemerintah yang mampu melaksanakan tugasnya secara efektif dan efisien.

Kemudian, menurut Wibowo (2007: 76), kinerja dapat diartikan sebagai prestasi kerja atau hasil kerja (output) baik kualitas maupun kuantitas, yang dicapai seseorang per periode dalam melaksanakan tugasnya sesuai dengan tanggungjawab yang diberikan kepadanya.
Dalam melakukan suatu pekerjaan, seorang aparat atau pegawai hendaknya memiliki kinerja yang tinggi, akan tetapi hal tersebut sulit untuk dicapai, bahkan banyak pegawai yang memiliki kinerja yang rendah atau semakin menurun. Pegawai yang baik adalah pegawai yang mampu memberikan kontribusi terhadap instansi tempat dia bekerja, tidak hanya terbatas pada tenaga tetapi juga pikiran, ide, agar semua yang mereka kerjakan bisa mendapatkan hasil maksimal baik dari segi kualitas, kuantitas, dan efisiensi waktu. Pegawaipun harus aktif dan berperan aktif dalam melaksanakan pekerjaannya sehingga mampu memberikan keuntungan terhadap instansi. Dalam hal ini pegawai adalah ujung tombak dari sebuah instansi.

Banyak faktor yang mempengaruhi prestasi kerja, salah satu di antaranya peran pegawai yang optimal berpengaruh terhadap pencapaian kinerja yang dapat dilihat dari efektivitas kerjanya. Selain perilaku pegawai, kinerja pegawai juga didukung oleh employee engagement. Employee engagement didefinisikan sebagai sejauh mana pegawai berkomitmen untuk sesuatu atau seseorang dalam organisasi mereka, seberapa keras mereka bekerja dan berapa lama mereka tinggal sebagai hasil dari komitmen. Pegawai akan dapat bekerja lebih rajin ketika mereka merasa terikat (engaged) secara psikologis kepada instansi. Instansi yang baik, haruslah membangun hubungan yang positif.

Selain daripada employee engagement, karakteristik individu juga berpengaruh terhadap prestasi kerja pegawai. Keistimewaan yang ada pada manusia adalah satu- satunya sumber daya di dalam instansi yang mempunyai pikiran, perasaan, dan kepribadian yang berbeda - berbeda. Kepribadian pegawai yang berbeda - beda menjadikan pegawai mempunyai ciri khas tersendiri sehingga membentuk suatu karakteristik individu pada pegawai. Baik buruknya karakteristik individu pegawai tergantung bagaimana mereka mengaplikasikannya.

Karakteristik individu yang berbeda-beda pada setiap individu menciptakan perbedaan pendapat yang berbeda-beda dan kontribusi kinerja yang berbeda juga pada instansi. Perbedaan pendapat menurut Colquitt (2009: 2273) adalah mengkaji kinerja dilihat dari perspektif perilaku normal, sedangkan Murphy (2002: 143) mengkaji kinerja berorientasi pada interpersonal dan perilaku mengurangi waktu. 
Sedangkan menurut pendapat Gibson at.al (2009:225) kinerja adalah sebagai bentuk seperangkat hasil yang diperoleh selama periode tertentu, tidak berhubungan dengan sifat karakteristik pribadi, kompetensi. Jadi Gibson berpendapat diperlukan perbedaan yang jelas antara pengukuran pegawai dan pengukuran kinerja. Gibson at.al (2009:227) juga mengemukakan bahwa kinerja sebagai out come yang pertama behavior yaitu meliputi tentang kepuasan kerja, performance, absen, pergantian, kecelakaan, penyalahgunaan, kepedulian terhadap kesehatan, yang kedua kognitif, dan yang ketiga yaitu psysiological. Pegawai dengan karakteristik yang baik akan menjadikan pegawai tersebut lebih mudah dalam mengerjakan pekerjaannya, sehingga kinerja yang dihasilkan menjadi optimal dan sangat baik pengaruhnya bagi instansi. Begitupun sebaliknya, pegawai dengan karakteristik yang buruk akan menghambat instansi dalam beroperasi dan berkembang. Berdasarkan hal itulah dapat dipastikan bahwa instansi memiliki kriteria tertentu mengenai pegawai yang akan mereka pekerjakan yang sesuai dengan kebutuhan instansi.

Faktor lain yang mempengaruhi prestasi kerja pegawai Kantor Kecamatan Medan Belawan adalah disiplin. Disiplin adalah merupakan bentuk pengendalian diri pegawai dan pelaksanaan yang teratur dan menunjukkan tingkat kesungguhan tim kerja di dalam sebuah organisasi (Ambar dan Rosidah, 2003) . Disiplin kerja merupakan pengendalian diri pegawai yang sesuai peraturan yang berlaku dan menunjukkan kesungguhan tim kerja di dalam sebuah organisasi (Simmamora, 2004). Di bidang pemerintahan, masalah disiplin tidaklah kalah penting, peranannya lebih besar karena menyangkut kepentingan umum, bahkan menjadi kepentingan rakyat secara keseluruhan. Manajemen disiplin yang diselenggarakan oleh pemerintah semakin terasa dengan adanya kesadaran bernegara dan bermasyarakat, maka kehadiran pegawai dalam manajemen disiplinnya telah meningkat kedudukannya di mata masyarakat menjadi suatu hak, yaitu hak atas pelayanan. Perhatian terhadap eksistensi disiplinnya semakin berkembang pula seiring dengan munculnya berbagai masalah dalam pelayanan pemerintah kepada rakyat. Pelayanan yang mahal, kaku dan terbelit - belit, sikap dan tindakan aparat, pelayanan yang suka menuntut imbalan, kurang ramah, arogan, dan lambat serta fasilitas pelayanan yang kurang memuaskan dan sebagainya merupakan fenomena - fenomena yang kerapkali mewarnai proses hubungan antara pemerintah dengan masyarakat berkaitan dengan proses pelayanan. Hal ini memberi isyarat bahwa kajian dan analisis masalah pelayanan masyarakat merupakan salah satu fenomena penting relevan dan actual untuk diteliti. Hal ini terjadi disebabkan karena salah satu faktor ketidakdisiplinan pegawai dalam mengurus administrasi pelayanan masyarakat yang menyebabkan lemahnya sistem pelayanan pada Kantor Kecamatan Medan Belawan adalah disiplin, kemudian masih ada pegawai yang tidak ada di tempat pada saat jam kerja, masih ada pegawai yang datang terlambat dan pulang sebelum jam kantor.

Berdasarkan uraian diatas, tujuan penelitian ini adalah sebagai berikut :

1. Untuk mengetahui dan menganilisis pengaruh employee engagement terhadap prestasi kerja pegawai di Kantor Kecamatan Medan Belawan

2. Untuk mengetahui dan menganilisis pengaruh karakteristik individu terhadap prestasi kerja pegawai di Kantor Kecamatan Medan Belawan

3. Untuk mengetahui dan menganilisis pengaruh disiplin kerja terhadap prestasi kerja pegawai di Kantor Kecamatan Medan Belawan

4. Untuk mengetahui dan menganilisis pengaruh employee engagement, karakteristik individu dan disiplin kerja terhadap prestasi kerja pegawai di Kantor Kecamatan Medan Belawan

\section{Metode Penelitian}

\subsection{Populasi dan Sampel}

Menurut Sugiyono (2004 : 90) populasi adalah wilayah generasi yang terdiri dari atas/subjek yang mempunyai kualitas karakteristik tertentu yang disajikan oleh peneliti untuk dipelajari dan kemudian ditarik kesimpulannya. Adapun jumlah populasi dan sampel dalam penelitian ini adalah 47 orang yaitu para pegawai Kantor Kecamatan Medan Belawan.

\subsection{Pengujian Validitas}

Pengujian validitas dilakukan dengan melakukan korelasi bilvariate antara masingmasing skor indikator dengan total skor konstruk. 
Tabel 1

Uji validitas variable employee engagement

\begin{tabular}{|c|c|c|c|}
\hline No butir & $\mathbf{r}_{\text {hitung }}$ & $\mathbf{r}_{\text {tabel }}$ $=\mathbf{0 , 0 5}(\mathbf{4 7})$ & Keterangan \\
\hline Butir 1 & 0,383 & 0.2816 & Valid \\
\hline Butir 2 & 0,583 & 0.2816 & Valid \\
\hline Butir 3 & 0,340 & 0.2816 & Valid \\
\hline Butir 4 & 0,342 & 0.2816 & Valid \\
\hline Butir 5 & 0,533 & 0.2816 & Valid \\
\hline
\end{tabular}

Sumber : Hasil pengolahan data 2019

Tabel 1. diatas diketahui bahwa seluruh pertanyaan pada setiap variabel telah memenuhi syarat validitas, yaitu $r$ hitung $>r$ tabel, dimana $\mathrm{r}$ tabel $=0.2816$. sehingga seluruh pertanyaan tersebut dapat digunakan untuk mengukur variabel penelitian.

Tabel 2

Uji validitas variable karakteristik individu

\begin{tabular}{|l|c|c|c|}
\hline No butir & $\mathbf{r}_{\text {hitung }}$ & $\mathbf{r}_{\text {tabel }}$ $=\mathbf{0 , 0 5}(\mathbf{4 7})$ & Keterangan \\
\hline Butir 1 & 0,353 & 0.2816 & Valid \\
\hline Butir 2 & 0,562 & 0.2816 & Valid \\
\hline Butir 3 & 0,432 & 0.2816 & Valid \\
\hline Butir 4 & 0,361 & 0.2816 & Valid \\
\hline Butir 5 & 0,705 & 0.2816 & Valid \\
\hline
\end{tabular}

Sumber : Hasil pengolahan data 2019

Tabel 2, diatas diketahui bahwa seluruh pertanyaan pada setiap variabel telah memenuhi syarat validitas, yaitu $r$ hitung $>r$ tabel, dimana $r$ tabel $=0.2816$. sehingga seluruh pertanyaan tersebut dapat digunakan untuk mengukur variabel penelitian.

Tabel 3

Uji validitas variable disiplin kerja

\begin{tabular}{|l|c|c|c|}
\hline No butir & $\mathbf{r}_{\text {hitung }}$ & $\mathbf{r}_{\text {tabel }}{ }^{\natural}=\mathbf{0 , 0 5} \mathbf{( 4 7 )}$ & Keterangan \\
\hline Butir 1 & 0,625 & 0.2816 & Valid \\
\hline Butir 2 & 0,282 & 0.2816 & Valid \\
\hline Butir 3 & 0,284 & 0.2816 & Valid \\
\hline Butir 4 & 0,506 & 0.2816 & Valid \\
\hline Butir 5 & 0,480 & 0.2816 & Valid \\
\hline Butir 6 & 0,523 & 0.2816 & Valid \\
\hline Butir 7 & 0,634 & 0.2816 & Valid \\
\hline Butir 8 & 0,290 & 0.2816 & Valid \\
\hline Butir 9 & 0,295 & 0.2816 & Valid \\
\hline Butir 10 & 0,339 & 0.2816 & \\
\hline
\end{tabular}

Sumber : Hasil pengolahan data 2019

Tabel 3, diatas diketahui bahwa seluruh pertanyaan pada setiap variabel telah memenuhi syarat validitas, yaitu $r$ hitung $>r$ tabel, dimana $\mathrm{r}$ tabel $=0.2816$. sehingga seluruh pertanyaan tersebut dapat digunakan untuk mengukur variabel penelitian.

Tabel 4

Uji validitas variable prestasi kerja

\begin{tabular}{|c|c|c|c|}
\hline No butir & $\mathbf{r}_{\text {hitung }}$ & $\mathbf{r}_{\text {tabel }}$ $=\mathbf{0 , 0 5}(\mathbf{4 7})$ & Keterangan \\
\hline Butir 1 & 0,580 & 0.2816 & Valid \\
\hline Butir 2 & 0,287 & 0.2816 & Valid \\
\hline
\end{tabular}




\begin{tabular}{|l|c|c|c|}
\hline No butir & $\mathbf{r}_{\text {hitung }}$ & $\mathbf{r}_{\text {tabel }}{ }=\mathbf{0 , 0 5} \mathbf{( 4 7 )}$ & Keterangan \\
\hline Butir 3 & 0,292 & 0.2816 & Valid \\
\hline Butir 4 & 0,520 & 0.2816 & Valid \\
\hline Butir 5 & 0,421 & 0.2816 & Valid \\
\hline Butir 6 & 0,547 & 0.2816 & Valid \\
\hline Butir 7 & 0,590 & 0.2816 & Valid \\
\hline Butir 8 & 0,338 & 0.2816 & Valid \\
\hline Butir 9 & 0,303 & 0.2816 & Valid \\
\hline Butir 10 & 0,388 & 0.2816 & Valid \\
\hline
\end{tabular}

Sumber : Hasil pengolahan data 2019

Tabel 4, diatas diketahui bahwa seluruh pertanyaan pada setiap variabel telah memenuhi syarat validitas, yaitu $r$ hitung $>r$ tabel, dimana $\mathrm{r}$ tabel $=0.2816$. sehingga seluruh pertanyaan tersebut dapat digunakan untuk mengukur variabel penelitian.

Tabel 5

Uji reliabilitas

\begin{tabular}{|l|c|c|c|}
\hline \multicolumn{1}{|c|}{ Variabel } & $\begin{array}{c}\text { Nilai alpha } \\
\text { cronbach }\end{array}$ & $\begin{array}{c}\text { Nilai } \mathbf{R}_{\text {tabel }} \\
\mathbf{N = \mathbf { 4 7 }}\end{array}$ & Keterangan \\
\hline Employee Engagement $\left(\mathrm{X}_{1}\right)$ & 0,589 & 0.2816 & Reliabel \\
\hline Karakteristik individu $\left(\mathrm{X}_{2}\right)$ & 0,652 & 0.2816 & Reliabel \\
\hline Disiplin kerja $\left(\mathrm{X}_{3}\right)$ & 0,649 & 0.2816 & Reliabel \\
\hline Prestasi kerja $(\mathrm{Y})$ & 0,638 & 0.2816 & Reliabel \\
\hline
\end{tabular}

Sumber : Hasil Pengolahan SPSS Versi 20

Untuk menguji reliabilitas yang paling sering digunakan kebanyakan peneliti dengan menggunakan CrobachAlpha. Berdasarkan table 5 diatas menunjukkan bahwa nilai alpha cronbach $>r_{\text {tabel }}$, sehingga disimpulkan bahwa semua butir pertanyaan pada variable penelitian dinyatakan reliable dan di pakai.

\subsection{Uji Asumsi Klasik}

\subsubsection{Uji Normalitas}

Pengujian normalitas data penelitian adalah untuk menguji apakah dalam model statistik variabel-variabel penelitian berdistribusi normal atau tidak normal. Model regresi yang tinggi adalah memiliki distribusi normal atau mendekati normal. Untuk menguji apakah distribusi data normal atau tidak, salah satunya dengan menggunakan metode gambar normal Probabilitas Plots digunakan untuk menyimpulkan apakah model analisis memenuhi asumsi normal, dengan penyebaran data di sekitar garis diagonal dan mengikuti arah garis diagonal maka data tersebut mememenuhi asumsi normal dalam model analisis, yang dapat dilihat pada gambar dibawah ini :

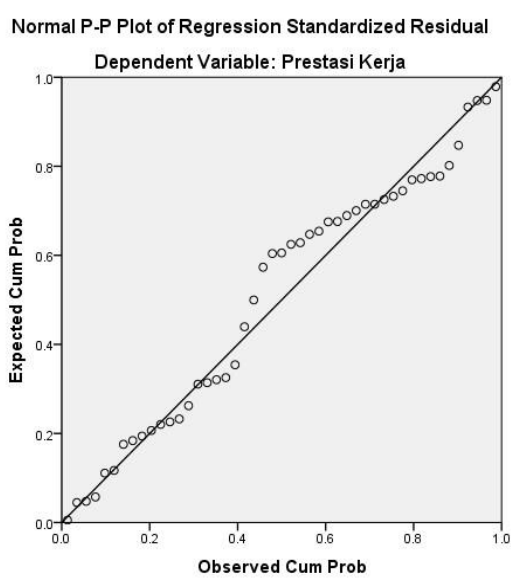

Gambar 1 Uji Normalitas

Berdasarkan gambar di atas, terlihat bahwa distribusi dari titik-titik data employee engagement, karakteristik individu, disiplin kerja dan prestasi kerja menyebar. Grafik P-P Plot diatas menunjukan bahwa sebaran data menyebar disekitar garis diagonal, sehingga asumsi normalitas dipenuhi. Maka model regresi layak dipakai untuk memprediksi Prestasi Kerja berdasarkan variabel independennya.

\subsubsection{Uji Multikolinearitas}

Uji Multikolinieritas dari hasil angket yang telah didistribusikan kepada respoden dapat dilihat pada tabel berikut. 
Tabel 6

Uji Multikolinearitas

Coefficients $^{\mathrm{a}}$

\begin{tabular}{|c|c|c|c|c|c|c|}
\hline \multirow{2}{*}{\multicolumn{2}{|c|}{ Model }} & \multicolumn{3}{|c|}{ Correlations } & \multicolumn{2}{|c|}{ Collinearity Statistics } \\
\hline & & Zero-order & Partial & Part & Tolerance & VIF \\
\hline \multirow{3}{*}{1} & $\begin{array}{l}\text { (Constant) } \\
\mathrm{X} 1\end{array}$ & 623 & 448 & 340 & 730 & 1370 \\
\hline & $\mathrm{X} 2$ & .421 & .422 & .315 & .908 & 1.101 \\
\hline & $\mathrm{X} 3$ & .485 & .384 & .282 & .780 & 1.283 \\
\hline
\end{tabular}

Berdasarkan table 6 diatas menunjukkan Hasil perhitungan nilai variance inflaction factor (VIF), lebih dari 10. Jadi dapat disimpulkan bahwa tidak ada multikolinieritas antar variabel independen dalam model regresi.

\subsubsection{Uji Heteroskedastisitas}

Uji heteroskedastisitas dilakukan untuk mengetahui apakah dalam sebuah model regresi terjadi ketidaksamaan varians dari residual suatu pengamatan ke pengamatan lain. Jika varians dari residual suatu pengamatan ke pengamatan lain tetap disebut heteroskedastisitas.

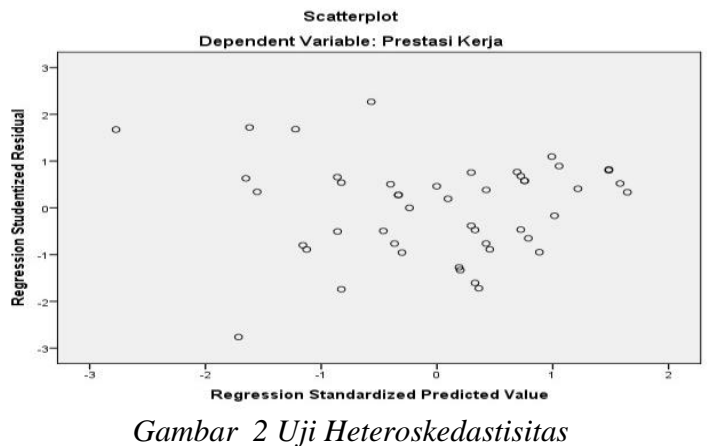

Tabel 7

Uji Simultan (Uji F)

ANOVAa

\begin{tabular}{|c|c|c|c|c|c|c|}
\hline \multicolumn{2}{|c|}{ Model } & Sum of quares & $\mathrm{df}$ & Mean Square & $\mathrm{F}$ & Sig. \\
\hline \multirow{3}{*}{1} & \multirow{2}{*}{$\begin{array}{l}\text { Regression } \\
\text { Residual }\end{array}$} & 288.518 & 3 & 96.17 & 118.83 & .000 \\
\hline & & 34.801 & 43 & .809 & & \\
\hline & Total & 323.319 & 46 & & & \\
\hline
\end{tabular}

b. Predictors: (Constant), Disiplin Kerja, Karakteristik Individu, Employee Engagement

Berdasarkan tabel 7 di atas dapat dilihat bahwa $F_{\text {hitung }}$ sebesar 118.83 sedangkan $F_{\text {tabel }}$ sebesar 2,580 dengan nilai probabilitas 0.05 . Probabilitas siginifikan jauh lebih kecil dari 0,05 yaitu $0,000<0,05$, maka model regresi dapat dikatakan bahwa dalam penelitian ini
Dari gambar di atas menunjukkan bahwa diagram pencar tidak membentuk suatu pola atau acak, dengan demikian dapat dikatakan bahwa regresi tidak mengalami gangguan heteroskedastisitas pada model regresi sehingga model regresi layak dipakai untuk mengetahui Prestasi Kerja pegawai (Y) berdasarkan variabel bebasnya.

\subsection{Uji Signifikan Simultan (Uji F)}

Uji F (uji simultan) dilakukan untuk melihat pengaruh variabel bebas terhadap variabel terikatnya secara serempak. Cara yang digunakan adalah dengan melihat level of significant $(=0,05)$. Jika nilai signifikansi lebih kecil dari 0,05 maka $\mathrm{H} 0$ ditolak dan $\mathrm{Ha}$ diterima. 
engagement, karakteristik individu dan disiplin

Tabel 8

Uji Parsial (Uji t)

Coefficients $^{\mathrm{a}}$

\begin{tabular}{|c|c|c|c|c|c|c|}
\hline \multirow{2}{*}{\multicolumn{2}{|c|}{ Model }} & \multicolumn{2}{|c|}{ Unstandardized Coefficients } & \multirow{2}{*}{$\begin{array}{c}\text { Standardized } \\
\text { Coefficients } \\
\text { Beta } \\
\end{array}$} & \multirow[t]{2}{*}{$\mathrm{t}$} & \multirow[t]{2}{*}{ Sig. } \\
\hline & & B & Std. Error & & & \\
\hline \multirow{4}{*}{1} & (Constant) & 1.846 & 2.755 & & .670 & .506 \\
\hline & $\mathrm{X} 1$ & .079 & .099 & .044 & .797 & .430 \\
\hline & $\mathrm{X} 2$ & -.162 & .094 & -.093 & -1.718 & .093 \\
\hline & X3 & .992 & .058 & .954 & 17.209 & .000 \\
\hline
\end{tabular}

a. Dependent Variable: $Y$

Berdasarkan tabel 8 diatas dapat dilihat bahwa :

a. Pengaruh employee engagement terhadap prestasi kerja pegawai. Pengujian signifikan dengan kriteria pengambilan keputusan: $\mathrm{Ha}$ diterima dan $\mathrm{HO}$ ditolak, apabila $\mathrm{t}_{\text {hitung }}>\mathrm{t}_{\text {tabel }}$ atau Sig. $\mathrm{t}<\alpha$, Ha ditolak dan $\mathrm{H} 0$ diterima, apabila $t_{\text {hitung }}<\mathrm{t}_{\text {tabel }}$ atau Sig. $\mathrm{t}>\alpha$. Nilai $t_{\text {hitung }}$ sebesar 0.797 sedangkan $t_{\text {tabel }}$ sebesar 2.014 dan signifikan sebesar 0,430, sehingga $\mathrm{t}_{\text {hitung }} 0.797<\mathrm{t}_{\text {tabel }} 2.014$ dan signifikan $0,430>0,05$, maka Ha ditolak dan $\mathrm{H} 0$ diterima, yang menyatakan employee engagement secara parsial tidak berpengaruh dan tidak siginifikan terhadap prestasi pegawai.

b. Pengaruh karakteristik individu terhadap prestasi kerja pegawai. Pengujian signifikan dengan kriteria pengambilan keputusan: Ha diterima dan $\mathrm{HO}$ ditolak, apabila $\mathrm{t}_{\text {hitung }}>\mathrm{t}_{\text {tabel }}$ atau Sig. $\mathrm{t}<\alpha$, Ha ditolak dan $\mathrm{H} 0$ diterima, apabila $t_{\text {hitung }}<t_{\text {tabel }}$ atau Sig. $t>\alpha$. Nilai $\mathrm{t}_{\text {hitung }}$ sebesar -1.718 sedangkan $\mathrm{t}_{\text {tabel }}$ sebesar 2.014 dan signifikan sebesar 0,093, sehingga $\mathrm{t}_{\text {hitung }}-1.718<\mathrm{t}_{\text {tabel }} 2.014$ dan signifikan

0,093 > 0,05, maka Ha ditolak dan H0 diterima, yang menyatakan karakteristik individu secara parsial berpengaruh negatif dan tidak siginifikan terhadap prestasi pegawai.

c. Pengaruh disiplin kerja terhadap prestasi kerja pegawai. Pengujian signifikan dengan kriteria pengambilan keputusan: Ha diterima dan HO ditolak, apabila $t_{\text {hitung }}>t_{\text {tabel }}$ atau Sig. $\mathrm{t}<\alpha$, Ha ditolak dan H0 diterima, apabila $\mathrm{t}_{\text {hitung }}<\mathrm{t}_{\text {tabel }}$ atau Sig. $\mathrm{t}>\alpha$. Nilai $\mathrm{t}_{\text {hitung }}$ sebesar 17.209 sedangkan $t_{\text {tabel }}$ sebesar 2.014 dan signifikan sebesar 0,093 , sehingga $t_{\text {hitung }}$ $17.209>\mathrm{t}_{\text {tabel }} 2.014$ dan signifikan $0,000<$ 0,05, maka Ha diterima dan H0 ditolak, yang menyatakan disiplin kerja secara parsial berpengaruh positif dan signifikan terhadap prestasi pegawai.

\subsection{Uji Determinasi (R Square)}

Analisis koefisien determinasi ini digunakan untuk mengetahui persentase besarnya variasi pengaruh variabel bebas terhadap variabel terikat.

Tabel 9

Uji Determinasi

\begin{tabular}{|l|c|r|r|r|}
\hline Model & $\mathrm{R}$ & R Square & $\begin{array}{c}\text { Adjusted R } \\
\text { Square }\end{array}$ & \multicolumn{1}{c|}{ Std. Error of the Estimate } \\
\hline 1 & $.945^{\mathrm{a}}$ & .892 & .885 & .89963 \\
\hline
\end{tabular}

a Predictors: (Constant), employee engagement, karakteristik individu, disiplin kerja

Dependent Variable: prestasi kerja

Berdasarkan tabel 9 di atas menunjukkan bahwa angka adjusted $R$ Square 0,885 yang disebut koefisien determinasi dan artinya bahwa $88.5 \%$ prestasi kerja pegawai dapat diperoleh dan dijelaskan oleh employee engagement, karakteristik individu dan disiplin kerja. Sedangkan sisanya $100 \%-88.5 \%=11.5 \%$ dijelaskan oleh faktor lain atau variabel diluar model.

\section{Kesimpulan}

Berdasarkan pada analisis dan evaluasi data di atas, maka kesimpulan dari penelitian ini adalah : 
1. Variable employee engagement secara parsial tidak berpengaruh dan tidak signifikan terhadap prestasi pegawai.

2. Variable karakteristik individu secara parsial berpengaruh negatif dan tidak signifikan terhadap prestasi pegawai

3. Variabel disiplin kerja secara parsial berpengaruh positif dan signifikan terhadap prestasi pegawai.

4. Variable employee engagement, karakteristik individu dan disiplin kerja secara simultan berpengaruh signifikan terhadap prestasi kerja

\section{DAFTAR PUSTAKA}

A.A Anwar Prabu Mangkunegara. (2009). Manajemen Sumber Daya Manusia. Bandung: PT Remaja Rosdakarya

Abdul Rahman, Agus. 2013. Psikologi Sosial: Integrasi Pengetahuan Wahyu dan Pengetahuan Empirik. Jakarta: Rajawali Pers.

Agustuti Handayani. 2010. Analisis Pengaruh Gaya Kepemimpinan dan Motivasi Kerja Terhadap Kinerja Pegawai Pada Balai Besar POM Provinsi Lampung. Vol 1, No 1, Januari-Juni.

Akbar, Muhammad Rizza. (2013). Pengaruh Budaya Organisasi Terhadap Employee engagement (Studi Pada Karyawan PT. PRIMATEXCO INDONESIA di Batang). Retrieved September 17, 2017

Albrecht, S. (2010). Handbook of Employee Engagement : Perspectives, Issues, Research and Practice. UK : Edward Elgar Publishing.

Alek S. Nitisemito. 2009. Manajemen Personalia. Edisi kedua. Jakarta: Ghalia.

Ambar T. Sulistiyani dan Rosidah. 2003. Manajemen Sumber Daya Manusia. Cetakan Pertama. Penerbit Graha Ilmu. Yogyakarta.

Anoraga, Pandji. 2004. Manajemen Bisnis. Jakarta: Penerbit Rineka Cipta. Bilson, Simamora. (2004). Riset Pemasaran. Jakarta: Gramedia Utama

Colquitt, J.A., Lepine, J.A., \& Wesson, M.J. (2009). Organizational behavior: Improving Performance and Commitment in the Workplace. McGrawHill.

Gibson. (2002). Organisasi Perilaku-strukturproses. Jakarta: Penerbit Erlangga

Hasibuan, Malayu. (2008). Manajemen Dasar, Pengertian, Dan Masalah. Jakarta: PT Bumi Aksara
Kahn, W. A., 1990. Psychological conditions of personal engagement and disengagement at work. Academy of Management Journal, Volume 33, pp. 692724.

Maylett, Tracy \& Paul Warner. (2014). MAGIC: Five Keys to Unlock the Power of Employee Engagement. Texas: Decision Wise, Inc

Muljasih, Endah. 2015. Hubungan antara persepsi organisasi (Perceived Organizational Support) dengan keterikatan karyawan (Employee Engagement). . Jurnal Psikologi Undip vol.14 No.1 April 2015, 4051

Murphy, Kevin J. (2002) "Explaining Executive Compensation: Managerial Power versus the Perceived Cost of Stock Options," University of Chicago Law Review: Vol. 69 : Iss. 3 , Article 4.

Nurofia, Fifie. 2005. Mengenal Employee Engagement. Repository. maranatha.edu/2598/1/Mengenal Employee Engagement. Artikel Employee Engagement

Purba, J. 2002. Pengelolaan Lingkungan Sosial : Kantor Menteri Negara Lingkungan Hidup. Yayasan Obor Indonesia. Jakarta.

Risher .(2010). Don't Overlook Frontline Supervisors. Public Manager, 39 (3): 7476. Robbins, Stephen P. (2006). Perilaku Organisasi. Jakarta: PT Indeks Kelompok Gramedia

Siagian, Sondang P, 2004, Prinsip-prisip Dasar Manajemen Sumber Daya Manusia, Jilid I, Penerbit Binarupa Aksara, Jakarta

Suryohadiprojo, S. $1989 . \quad$ Peranan Kepemimpinan dalam Menegakkan Disiplin Masyarakat. Jurnal CSIS. No.4, Th.XVIII. Juli-Agustus. Jakarta : Centre for Strategic and International Studies.

Sutrisno, Edy. (2011). Manajemen Sumber Daya Manusia. Jakarta: Kencana

Vazirani, N. 2007. Employee Engagement. Working Paper Series. Mumbai : SIES College of Management Studies

Veithzal, Rivai. (2004). Manajemen Sumber Daya Manusia Untuk Perusahaan. Jakarta: PT. Raja Grafindo Persada

Vibrayani. 2012. Peran Transformasional Leadership terhadap Employee Engagement. UGM: Tesis Fakultas Ekonomika dan Bisnis 
Wibowo. (2007). Manajemen Kinerja. Jakarta: PT Raja Grafindo Persada

Yuspratiwi, I. 1990. Hubungan Antara Locus of Control dengan Disiplin Kerja Wiraniaga pada Wiraniaga Obat-obatan di DIY. Skripsi Fakultas Psikologi UGM. Yogyakarta: tidak diterbitkan. 